\title{
CONTRIBUIÇÕES DE UMA SEQUÊNCIA DIDÁTICA: RESULTADOS DE UM PRÉ E PÓS-TESTE DE ESTATÍSTICA
}

\author{
CONTRIBUITIONS OF A DIDACTIC SEQUENCE: RESULTS OF PRE AND POST-TEST \\ OF STATISTIC
}

\author{
Willian Damin \\ Universidade Tecnológica Federal do Paraná, wdamin@uenp.edu.br \\ Guataçara dos Santos Junior \\ Universidade Tecnológica Federal do Paraná,guata@utfpr.edu.br \\ Rudolph dos Santos Gomes Pereira \\ Universidade Estadual do Norte do Paraná, rudolphsantos@uenp.edu.br
}

\begin{abstract}
Resumo
Este artigo tem o objetivo de apresentar os resultados de um pré e pós-teste, partes de uma pesquisa que investigou a aprendizagem sobre conteúdos de Estatística básica a partir da aplicação de uma sequência didática. Participaram da pesquisa oito alunos (aproximadamente, 14 anos de idade) do 9o (nono) ano do Ensino Fundamental de um colégio da rede privada do estado do Paraná, Brasil. Todos os alunos participaram de um pré-teste, uma sequência didática e um pós-teste. Os resultados do pré-teste revelaram que os alunos apresentavam dificuldades em calcular medidas de tendência central, organizar, analisar e construir tabelas e gráficos. Após a aplicação da sequência didática observou-se avanços significativos na aprendizagem de conteúdos de Estatística pelos alunos participantes.
\end{abstract}

Palavras-chave: Ensino de Estatística; Pré-teste; Pós-teste.

\section{Abstract}

This article aims to present the results of a pre and post-test, parts of a study that investigated learning about basic statistical content from the application of a didactic sequence The participants were eight students (approximately 14 years old) of the 9th (ninth) grade of elementary school of a Private School of Paraná State, Brazil. All students participated in a pre-test, a didactic sequence and a post-test. The results in a pre-test revealed that the students had difficulties in calculating measures of central tendency, organize, analyze and build tables and graphs. After application of the didactic sequence was observed significant advances in learning Statistical content by participating students.

Keywords: Statistics Teaching; Pre-test; Post-test. 


\section{Introdução}

As diversas informações veiculadas na atual sociedade podem ser questionadas com a ajuda da Estatística no caso de haver dúvidas quanto a veracidade dos dados, pois existe a possibilidade de não representarem a verdadeira realidade dos fatos. É esse questionamento de veracidade que o ensino de Estatística também busca despertar em seus cidadãos. Para tanto, é necessário saber ler e interpretar as informações que são disponibilizadas pela mídia para os cidadãos, considerando que essa preparação para se tornar um cidadão estatisticamente letrado deve ser iniciada nos anos iniciais do Ensino Fundamental (LOPES, 1998, 2003; EVANGELISTA; GUIMARÃES, 2015).

Nos anos finais do Ensino Fundamental, habilidades como a coleta e a organização de dados, leitura e interpretação de gráficos e tabelas, devem ser aprimorados, ampliados e outros acrescentados, como os conceitos de medidas de tendência central. Trabalhar o ensino de Estatística é um desafio para o professor de Matemática, pois cabe a ele proporcionar oportunidades de conhecimento junto aos limites e possibilidades do Ensino Fundamental. Buscar aporte teórico e novas metodologias é fundamental no desenvolvimento adequado no ensino da Estatística, bem como pode possibilitar uma melhor compreensão por parte dos alunos.

Uma das possibilidades é o trabalho com a aplicação de um pré-teste, uma intervenção um ensino e de um pós-teste, no intuito de conhecer as dificuldades dos alunos e trabalhar para saná-las. Nessa perspectiva, pode-se destacar que algumas pesquisas (LEITE, 2010; WALICHINSKI, 2012; EVANGELISTA; GUIMARÃES, 2015) também realizaram esses procedimentos.

Uma análise preliminar do ambiente em que se vai trabalhar interfere na escolha de uma sequência de ensino ou uma sequência de atividades. A validação dos resultados obtidos com a aplicação de uma sequência pode ser obtida na confrontação entre pré e pós-teste. Com a análise dos resultados ainda é possível verificar as dificuldades dos alunos ainda existentes, podendo ser retomado o conteúdo em questão. Assim, ressaltase que o objetivo desse artigo é apresentar os resultados de um pré e pós-teste, partes de uma pesquisa que investigou a aprendizagem sobre conteúdos de Estatística básica a partir de uma sequência didática ${ }^{1}$.

\section{Os conteúdos de Estatística para os anos finais do Ensino Fundamental}

De acordo com as Diretrizes Curriculares Estaduais (DCE) de Matemática do estado do Paraná, o tema Estatística aparece no Conteúdo Estruturante Tratamento da Informação, que engloba os seguintes conteúdos para o Ensino Fundamental: Noções de probabilidade; Estatística; Matemática financeira; e Noções de análise combinatória.

Esses temas que estão inseridos no bloco Tratamento da Informação, podem contribuir para o desenvolvimento crítico do aluno, de forma que ele possa interpretar as

\footnotetext{
${ }^{1}$ A sequência didática foi ocultada por não ser o objetivo do artigo apresentá-la. Ela pode ser encontrada em Damin (2014).
} 
informações ocorridas na sociedade e com base em tabelas e gráficos ele interprete e descreva dados estatísticos (PARANÁ, 2008).

Propõe-se que esse trabalho de construção de conhecimento e de significados "[..] se faça por meio de um processo investigativo, pelo qual o estudante manuseie dados desde sua coleta até os cálculos finais [...]" (PARANÁ, 2008, p. 60).

Com base nas DCE (PARANÁ, 2008) elaborou-se o quadro 1, no qual podem ser observados os Conteúdos Básicos prescritos para os anos finais do Ensino Fundamental e a Avaliação, que são expectativas de aprendizagem.

Quadro 1 - Conteúdos Básicos referentes à Estatística.

\begin{tabular}{|c|c|c|}
\hline ANO & CONTEÚDOS BÁSICOS & AVALIAÇÃO \\
\hline 60 & Dados, tabelas e gráficos. & $\begin{array}{l}\text { Interprete e identifique os diferentes tipos de gráficos e } \\
\text { compilação de dados, sendo capaz de fazer a leitura } \\
\text { desses recursos nas diversas formas em que se } \\
\text { apresentam. }\end{array}$ \\
\hline $7^{0}$ & $\begin{array}{l}\text { Pesquisa Estatística; } \\
\text { Média Aritmética; Moda e } \\
\text { mediana. }\end{array}$ & $\begin{array}{l}\text { Analise e interprete informações de pesquisas } \\
\text { estatística; } \\
\text { Leia, interprete, construa e análise gráficos; } \\
\text { Calcule a média aritmética e a moda de dados } \\
\text { estatísticos. }\end{array}$ \\
\hline $8^{\circ}$ & $\begin{array}{l}\text { Gráfico e Informação; } \\
\text { População e amostra. }\end{array}$ & $\begin{array}{l}\text { Interprete e represente dados em diferentes } \\
\text { gráficos; } \\
\text { Utilize o conceito de amostra para levantamento de } \\
\text { dados. }\end{array}$ \\
\hline $9^{\circ}$ & Estatística. & $\begin{array}{l}\text { Embora nas DCE (PARANÁ, 2008), a Estatística } \\
\text { esteja definida como conteúdo básico, na página } 80 \\
\text { não há nenhum objetivo proposto para a avaliação. } \\
\text { Somente os conteúdos de Probabilidade, Combinação } \\
\text { e Juros Compostos são mencionados. }\end{array}$ \\
\hline
\end{tabular}

Fonte: Adaptado das DCE (PARANÁ, 2008)

Assim, espera-se que o aluno, ao final do Ensino Fundamental, saiba coletar e organizar dados e construir gráficos e tabelas (PARANÁ, 2008), tenha domínio e saiba utilizar as ferramentas estatísticas de forma significante para exercer a cidadania (BRASIL, 1998), uma vez que tais conteúdos, dentro do contexto de ensino e de aprendizagem, visam a aquisição e o desenvolvimento do raciocínio estatístico de forma a desenvolver indivíduos críticos e reflexivos, que saibam interpretar as diversas informações encontradas em seu cotidiano.

Visto que os conceitos descritos devem fazer parte da vida do aluno e que as DCE apresentam um aporte teórico reduzido sobre o tema Estatística nos anos Finais do Ensino Fundamental, ressalta-se assim a importância de pesquisas, trabalhos e materiais de apoio no que concerne ao Ensino de Estatística (WALICHINSKI, 2012). 


\section{Metodologia}

Esta pesquisa foi realizada com oito alunos, com aproximadamente 14 anos de idade do 9o (nono) ano do Ensino Fundamental de um colégio da rede privada de um município do norte do Paraná, Brasil. Os dados desta pesquisa foram coletados durante a aplicação de um pré e pós-teste, feitas pelo pesquisador por meio de atividades escritas realizadas pelos alunos.

A análise dos dados foi de cunho interpretativo, que segundo Rosa (2009) é baseada em dois aspectos: i) as análises sobre os dados coletados são influenciadas por concepções e interpretações daqueles que coletam e analisam os dados; ii) a investigação da própria prática pode, em diferentes circunstâncias, influenciar as características dos dados coletados bem como as análises realizadas.

Com o objetivo de identificar os conhecimentos e as dificuldades dos alunos participantes da pesquisa elaborou-se uma avaliação diagnóstica denominada pré-teste com seis questões que envolvia conceitos básicos de Estatística, como leitura e interpretação de gráficos e tabelas, média, mediana e moda. Essa avaliação foi aplicada novamente, denominada de pós-teste, após a sequência didática desenvolvida. $O$ intuito foi o de comparar pré e pós-teste, para analisar as contribuições da sequência didática.

Cabe ressaltar que a sequência didática desenvolvida, com atividades de uma pesquisa estatística, foi trabalhada dentro do contexto dos alunos, na qual eles puderam coletar, organizar e representar os dados coletados, de forma a investigar uma situação proposta por eles mesmos, construindo sentindo no que aprendem.

As questões que compõem o pré e o pós-teste estão de acordo com a idade cognitiva dos alunos respeitando o Projeto Político Pedagógico do colégio e foram adaptadas dos trabalhos de Walichinski (2012), Olimpíadas Brasileiras de Matemática das Escolas Públicas (OBMEP) de 2009 e Sistema de Avaliação de Rendimento Escolar do Estado de São Paulo (SARESP) de 2005. As questões são descritas a seguir juntamente com a discussão de cada uma delas.

\section{Discussão e resultados}

O objetivo da aplicação das avaliações diagnósticas consistiu em fazer comparações entre pré-teste e pós-teste, no intuito de indicar os avanços conquistados com a aplicação da sequência didática e identificar as dificuldades ainda existentes. As questões que compõe o pós-teste foram as mesmas do pré-teste.

\section{QUESTÃO 1}

No quadro 1 são apresentadas questões sobre a medida descritiva média aritmética e envolvia uma de suas propriedades, na qual a média é influenciada por todos os valores que compõe o conjunto de dados. 


\section{Quadro 2 - Questão 1}

1) Considere um grupo de pessoas com as seguintes idades em anos: 16, 54, 67, 48, 25, e 12.

a) Qual é a média aritmética da idade desse grupo?

b) Se mais uma pessoa de 28 anos se juntar ao grupo, qual será a nova média aritmética?

\section{Fonte: Autores}

A partir do item 1a), verificou-se que $75 \%$ dos alunos apresentaram dificuldades em determinar a média aritmética, como também encontrado por Walichinski (2012) ao aplicar um pré-teste e verificar que os alunos participantes não compreendiam o significado de média. As respostas desses alunos indicam a ausência do conceito de média aritmética até mesmo como algoritmo, o que evidencia que o tema Estatística foi pouco trabalhado com a turma nos anos anteriores.

Um aluno somou todos os dados, porém não dividiu o resultado pela quantidade de pessoas existentes no grupo. Esse erro vai ao encontro do estudo realizado por Magina et al. (2010), na qual os alunos realizavam apenas a soma dos valores do conjunto de dados, uma das concepções errôneas mais frequentes observados por esses autores. Outro aluno apenas separou as idades em pares, como forma de explicação.

A partir da análise do item 1a) do pós-teste, verificou-se que 87,5\% dos alunos determinaram a média aritmética de forma correta, um aumento de $62,5 \%$ em relação ao pré-teste. Apenas um aluno não resolveu esse item da questão.

Com relação ao item $1 b)$ do pré-teste, constatou-se que os mesmos dois alunos que responderam de forma correta o item 1a) também acertaram esse item, isto é, $25 \%$ dos alunos. Os erros cometidos foram o de não dividir a média pelo número total de termos.

No pós-teste, item 1b), 75\% dos alunos determinaram a nova média aritmética, 0 que significou um aumento de $50 \%$ de acerto quando comparado com o pré-teste. Um aluno cometeu erros ao dividir valores, como também apontado por Walichinski (2012) em sua pesquisa, ao salientar a dificuldade de alguns alunos em realizar a divisão. Nessa perspectiva, Pagan (2010) salienta que mesmo com esse erro, o aluno apresenta compreensão de média aritmética, pois pensou de forma correta, cometendo deslize em cálculos matemáticos.

Após a aplicação da sequência didática, o resultado obtido com base na comparação entre pré e pós-teste, indica um aumento significativo em relação á compreensão de média aritmética, mesmo não atingindo a todos os alunos participantes da pesquisa. Acredita-se que esse trabalho com média aritmética deve ser continuado nos anos posteriores, de forma a aprofundar esse conteúdo, visando a necessidade e a utilização de ferramentas estatísticas na sociedade atual.

\section{QUESTÃO 2}

A questão 2 tratava da interpretação de uma tabela como mostra o quadro 2. 


\section{Quadro 3-Questão 2}

2) Após medir a altura de cada um dos 27 alunos de uma turma, o professor resumiu os resultados obtidos em 5 classes, cujas frequências estão na tabela abaixo. É correto afirmar que:

\begin{tabular}{c|c}
\multicolumn{2}{c}{ Tabela 1 - Altura dos alunos da turma A } \\
\hline Altura (em metros) & Frequência \\
1,52 a 1,55 & 7 \\
1,56 a 1,59 & 9 \\
1,60 a 1,63 & 5 \\
1,64 a 1,67 & 4 \\
1,68 a 1,72 & 2 \\
\hline
\end{tabular}

Fonte: Saresp (2005)

(A) 7 alunos têm altura entre $1,60 \mathrm{~m}$ e $1,63 \mathrm{~m}$.

(B) 16 alunos têm altura menor que $1,60 \mathrm{~m}$.

(C) 4 alunos têm altura entre $1,60 \mathrm{~m}$ e $1,63 \mathrm{~m}$.

(D) 5 alunos têm altura entre $1,68 \mathrm{~m}$ e $1,72 \mathrm{~m}$.

\section{Fonte: São Paulo (2005)}

Dois alunos marcaram a alternativa correta, o que representa $25 \%$ do total de alunos que realizaram o pré-teste. Os demais alunos, ou seja, $75 \%$, não marcaram nenhuma das alternativas o que mostra que parte dessa turma não conseguiu interpretar uma tabela simples. Os documentos oficiais (DCE e PCN) que abordam sobre o conteúdo de Estatística, descrevem que ao final do Ensino Fundamental é necessário que o aluno conheça o conceito de uma tabela e saiba trabalhar com as diferentes representações dos dados. Observa-se que esse conceito não foi apreendido por essa turma e pode-se considerar que o raciocínio estatístico desses alunos ainda era frágil e faltava a compreensão completa de um determinado problema que envolvia a interpretação de dados.

Com base nos dados analisados, observou-se que na questão 2 do pós-teste houve um aumento de $67,5 \%$ em relação ao pré-teste, que era de $25 \%$ e passou a $87,5 \%$, ou seja, apenas um aluno não foi contemplado de forma satisfatória com a aplicação da sequência, pois, não marcou nenhuma das opções apresentadas. Dessa forma, pode-se dizer que os alunos compreendem de forma considerável a leitura e interpretação de tabelas, aproximando do trabalho de Vasconcelos (2007), ao esperar que os alunos apresentem habilidades em fazer uma leitura global dos dados que são apresentados em uma tabela simples.

O resultado satisfatório pode ser explicado pelo fato da aplicação da sequência didática contemplar a construção de tabelas e a manipulação dos dados obtidos durante a coleta, bem como a passagem desses dados para a representação gráfica, como previsto nos documentos oficiais.

[...] é importante o aluno conhecer fundamentos básicos de Matemática que permitam ler e interpretar tabelas e gráficos, conhecer dados estatísticos [...] é necessário que o aluno colete dados, organize-os em tabelas segundo o conceito de frequência e avance para as contagens, os cálculos de média, frequência relativa, frequência acumulada, mediana e moda (PARANÁ, 2008, p. 61). 
Dessa forma, destaca que a sequência didática, ao abordar a construção de tabelas e gráficos, proporcionou contributos para a aprendizagem de leitura e interpretação, a citar, a organização e tabulação dos dados; e o raciocínio utilizado para fazer a transição entre as diversas formas de representação de dados. Assim, com base nos resultados obtidos, salienta o desenvolvimento proporcionado à formação estatística dos alunos e espera-se que eles sejam capazes de utilizar os conceitos vistos em sala de aula em outras situações de tomada de decisões.

\section{QUESTÃO 3}

A terceira questão estava relacionada com a interpretação de um gráfico de barras como mostra o quadro 3.

\section{Quadro 4 - Questão 3}

3) (OBMEP - 2009) Os alunos do sexto ano da Escola Municipal Quixajuba fizeram uma prova contendo 5 questões. O gráfico mostra quantos alunos acertaram o mesmo número de questões; por exemplo, 30 alunos acertaram 4 questões. Qual das afirmações a seguir é verdadeira? Justifique sua resposta.

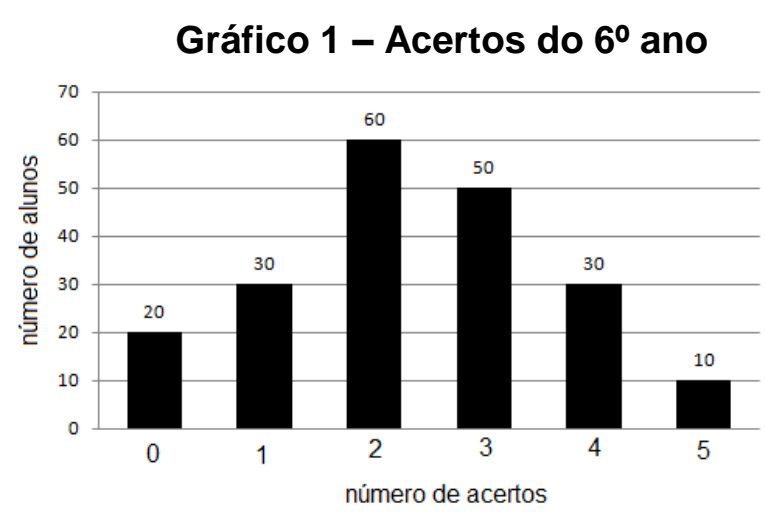

Fonte: Obmep

A) apenas $10 \%$ do total de alunos acertaram todas as questões.

B) a maioria dos alunos acertou mais de 2 questões.

C) menos de 200 alunos fizeram a prova.

D) 40 alunos acertaram pelo menos 4 questões.

E) exatamente $20 \%$ do total de alunos não resolveram nenhuma questão.

Fonte: Adaptado de Brasil (2009)

Dos oito alunos que realizaram o pré-teste, apenas um aluno marcou a alternativa correta, porém não justificou sua resposta como pedido na questão. Seis alunos não responderam a essa questão. Um aluno marcou a alternativa E) e justificou sua resposta de forma errônea, como mostra a figura a seguir.

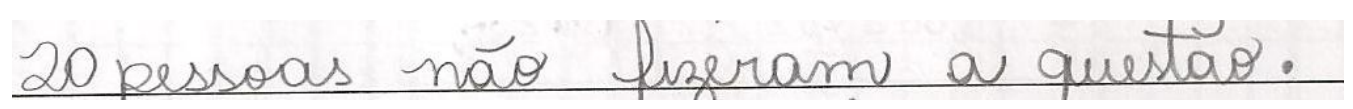

Figura 1- Resposta de aluno

Fonte: Autores 
Acredita-se que esse aluno tenha confundido o eixo da quantidade de alunos que marcava 20 como sendo os alunos que não acertaram nenhuma questão com $20 \%$ que aparecia na alternativa. Assim, 100\% dos alunos não responderam de forma adequada a essa questão. Esse resultado pode ser consequência da falta da capacidade de ler e interpretar gráficos, que vai ao encontro dos resultados obtidos por Estevam (2010) que verificou ao aplicar uma atividade que envolvia análise dos dados, que cerca de $90 \%$ dos alunos não desempenharam esse raciocínio.

Com a aplicação do pós-teste, verificou-se que três alunos marcaram a opção correta e justificaram de forma considerável a questão, totalizando $37,5 \%$ de acerto e aproximando dos achados por Vasconcelos (2007), ao também encontrar um resultado tímido no desempenho dos alunos de uma $8^{\mathrm{a}}$ série $\left(9^{\circ}\right.$ ano), frente a interpretação de gráficos. Esse desempenho pode ser levado em conta, quando aparecem dificuldades em realizar leitura dos dados quando não são apresentados explicitamente, ou ainda, quando se faz necessário a comparação de dados, como no caso da questão apresentada.

Em face ao exposto, é possível dizer que houve um aumento no desempenho quanto a leitura e interpretação de gráficos por parte de alguns alunos, contudo, as atividades desenvolvidas não atingiram plenamente a todos e é possível que um tempo maior seja necessário, de forma a poder atender efetivamente o desenvolvimento do letramento estatístico por todos e contribuir ainda mais para o estudo.

\section{QUESTÃO 4}

A seguir, a questão 4, que era necessário determinar a mediana e a moda.

\section{Quadro 5 - Questão 4}

4) Os números de pontos feitos em 11 jogos por um time de basquete foram: 100, 82, 93, $88,87,90,90,85,100,100,74$.

a) Qual é o valor da mediana nesses 11 jogos?

b) Qual é a moda desses resultados?

\section{Fonte: Adaptado de São Paulo (2005)}

De acordo com os resultados do item 4a) dessa questão, $87,5 \%$ dos alunos não souberam responder qual era o valor da mediana, isto é, $12,5 \%$ de acerto. Assim, apenas um aluno informou o valor correto dessa medida. Seis alunos não responderam a questão e outro respondeu o valor 82 como resposta. Já no pós-teste verificou-se que $62,5 \%$ dos alunos encontraram a mediana em um conjunto de dados referente a questão. Acredita-se que esse aumento tenha sido significativo, pois, quando comparado com o pré-teste, houve um aumento de 50\%. Porém, compartilha-se da ideia de Leite (2010) de que a mediana é a medida de maior dificuldade para os alunos, pois, alguns deles não foram capazes de organizar os dados de forma correta para determinação da mediana, mesmo com esse conteúdo trabalhado na sequência didática.

Com relação a determinação da moda, item 4b), 100\% dos alunos não encontraram essa medida. Um dos alunos calculou a média aritmética em vez de determinar a moda. Para encontrar essa medida de tendência central não era necessário realizar qualquer tipo de cálculo, mas sim conhecer o conceito dessa medida e saber 
diferenciá-la das outras. Esse resultado se difere quando comparado com o pós-teste, na qual todos os alunos calcularam a moda de forma correta. $O$ resultado encontrado na presente pesquisa vai ao encontro daqueles mostrados por Walichinski (2012), onde obteve $100 \%$ de aproveitamento na determinação dessa medida de tendência central e aponta que os alunos passaram a compreender o significado de moda.

De acordo com o pré-teste os alunos participantes não apresentavam conhecimento sobre medidas de tendência central, em particular o de mediana e moda. Com a aplicação de uma série de atividades previamente planejadas, que compunham a sequência didática, pautada na realidade do aluno, houve favorecimento na aquisição de conhecimentos estatísticos.

\section{QUESTÃO 5}

O quadro 5 ilustra a quinta questão, que envolvia a determinação da média aritmética e da moda, por interpretação de um gráfico de barras.

\section{Quadro 6 - Questão 5 do pré-teste}

5) Em uma prova de Matemática realizada pelos 40 alunos de uma turma, as notas foram números inteiros de 1 a 10. O gráfico de barras abaixo mostra a frequência das notas.

\section{Gráfico 2 - Notas do 8ㅇ ano}

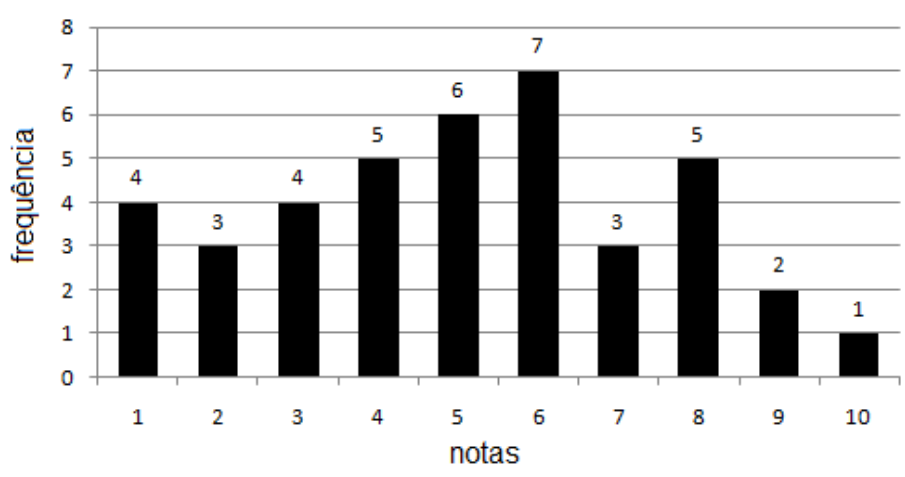

Fonte: Pesquisador

a) Qual foi a nota média aproximada dessa turma?

b) Qual a moda?

\section{Fonte: Autores}

Com relação ao item $5 a)$ dessa questão no pré-teste, um aluno (12,5\%) respondeu de forma correta, enquanto que $87,5 \%$ do total de alunos erraram ou não responderam qual a média aritmética das notas da turma. Dois alunos responderam que a média era 6 , e acredita-se que tenham interpretado o valor da moda como sendo o de média aritmética. Com base nos resultados do pós-teste verificou-se que $62,5 \%$ dos alunos determinaram a média aritmética de forma correta, um aumento de $50 \%$ quando comparado com o pré-teste. Ressalta-se que para a determinação da média era necessário a leitura e interpretação de um gráfico de barras. 
No entanto, o item 5b) que se tratava em determinar a moda, nenhum aluno respondeu de forma correta. Um aluno escreveu como resposta o valor 10 , confundindo esse valor com frequência, o que mostra as dificuldades dos alunos em determinar medidas de tendência central e inclusive na interpretação de gráficos. Stella (2003) apresenta resultados onde os alunos interpretam média aritmética como moda e salienta que essas medidas não são trabalhadas com distinção para favorecer o aluno a refletir qual medida é mais significativa.

Com relação ao conceito de moda, Walichinski (2012) descreve que a maioria dos alunos participantes de sua pesquisa apresentaram uma noção intuitiva sobre essa medida já no pré-teste. Esta constatação é diferente dos resultados encontrados aqui, já que todos alunos não demonstraram compreensão de moda.

No pós-teste, o aumento foi significativo, pois sete dos oito participantes, $87,5 \%$, encontraram o valor da moda. O resultado é relevante, pois o pré-teste indicou que nenhum aluno conseguiu determinar a moda nesse item $5 \mathrm{~b}$ ).

Os resultados apresentados mostram que o conceito de média aritmética e moda foram assimilados pelos alunos, pois conseguiram realizar uma leitura do gráfico de barras para determinar essas medidas. Vasconcelos (2007) salienta que esse tipo de questão está cada vez mais comum em situações do cotidiano, justificando a necessidade de interpretar e tomar decisões com base em representações gráficas. Entende-se que os alunos participantes da pesquisa poderão mobilizar conceitos de medidas de tendência central em um contexto gráfico. Destaca-se também que, parecem estar preparados para a apreensão e desenvolvimentos de novos conceitos relativos à Estatística.

\section{QUESTÃO 6}

A seguir, apresenta-se a última questão na qual era necessário fazer a representação gráfica com base em uma tabela de dupla entrada.

\section{Quadro 7 - Questão 6 do pré-teste}

6) O professor de Educação Física perguntou aos alunos de uma turma do 9ำ ano qual era o esporte preferido deles. Todos os alunos responderam indicando um esporte apenas. O resultado dessa consulta pode ser visto na seguinte tabela.

Tabela 2 - Esporte preferido de meninos e meninas

\begin{tabular}{c|c|c|c|c}
\hline Esporte preferido & \multicolumn{2}{|c|}{ Como praticante } & \multicolumn{2}{c}{ Como espectador } \\
\cline { 2 - 5 } & Meninos & Meninas & Meninos & Meninas \\
\hline Basquete & 2 & 3 & 2 & 2 \\
Futebol & 10 & 2 & 5 & 6 \\
Vôlei & 1 & 5 & 6 & 1 \\
Tênis & 0 & 4 & 2 & 7 \\
Outros & 2 & 3 & 0 & 1 \\
Total & 15 & 17 & 15 & 17 \\
\hline
\end{tabular}

Fonte: Walinchiski (2012) 
$\mathrm{Na}$ malha quadriculada abaixo $^{2}$, represente por meio de um gráfico de barras duplas, a preferência dos meninos e das meninas em relação ao esporte praticado pelos mesmos, conforme informações da tabela anterior.

\section{Fonte: Walinchiski (2012)}

Com base no pré-teste, um aluno, $12,5 \%$ do total, representou de forma correta o gráfico de barras duplas que era pedido na questão 6 , com relação a preferência dos meninos e meninas como praticante de esportes. Dois alunos deixaram a questão em branco e 5 alunos não interpretaram de maneira correta a questão e assim, representaram a tabela de dupla entrada de diversas maneiras. Na pesquisa realizada por Walichinski (2012) observa-se que $50 \%$ dos alunos também cometeram diversos erros de representação, como o de construir dois gráficos de barras simples. Segue um exemplo a seguir, que mostra a noção que eles apresentavam sobre representação gráfica quando se trata de gráfico de barras duplas.

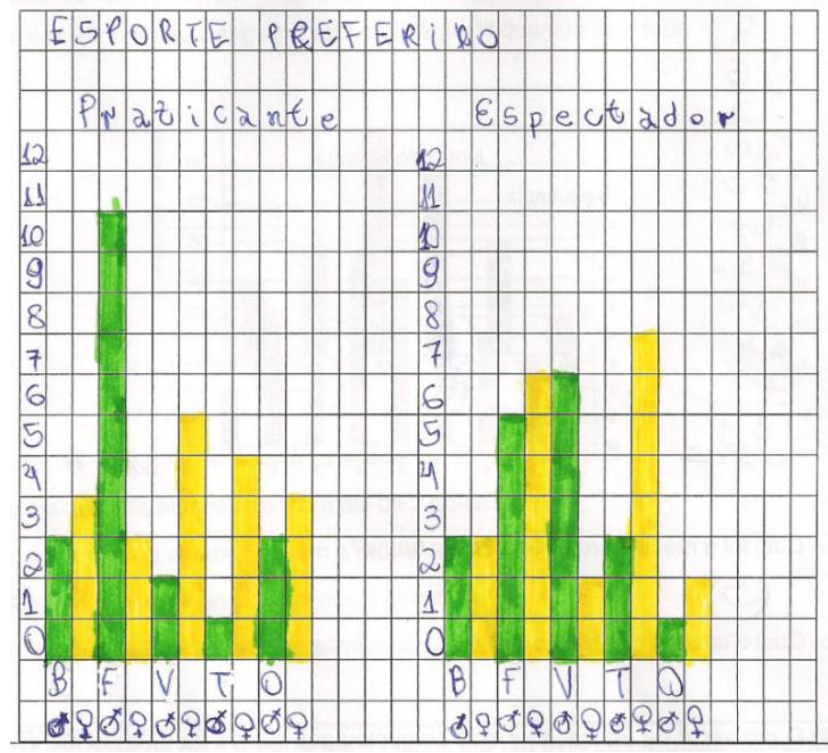

Figura 2 - Resposta de aluno

Fonte: Autores

Percebe-se que esses alunos não apresentaram a habilidade em fazer a transformação das informações de uma representação tabular para a representação gráfica, bem como mostraram dificuldades em representar de forma correta um gráfico.

Em comparação entre as avaliações diagnósticas, verificou-se um aumento de $12,5 \%$ do pré-teste para $75 \%$ no pós-teste. Os alunos construíram de forma correta o gráfico, com variável e legenda. Dessa forma, considera um bom rendimento da turma, pois houve um aumento de $62,5 \%$ nessa questão. A figura a seguir ilustra a resposta dada por um dos alunos.

\footnotetext{
2 Uma malha quadriculada aparecia junto com a questão. Optou-se em não apresentá-la por questão de espaço.
} 


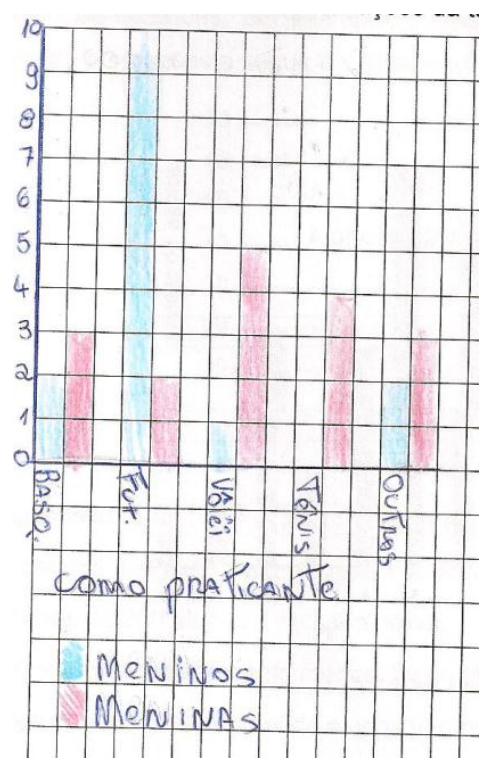

Figura 3 - Resposta de aluno Fonte: Autores

Observa-se que o resultado encontrado se assemelha ao de Walichinski (2012), na qual obteve $72,73 \%$ de acertos em sua análise. Vasconcelos (2007), após sua intervenção de ensino obteve quase $70 \%$ de acerto em uma questão onde os dados estavam representados em uma tabela e era necessário a construção gráfica.

Quanto aos erros cometidos no pós-teste, destaca-se que um dos alunos não resolveu essa questão, enquanto o outro erro encontrado foi a falta de atenção quanto a determinação das variáveis, bem como a construção de gráficos de barras simples ao invés do gráfico de barras duplas. Esse erro também foi encontrado por Walichinski (2012) na qual seus alunos representaram os dados da tabela em dois gráficos de barras simples com valores incorretos.

As competências estatísticas esperadas no desenvolvimento da sequência estatística foram contempladas e pode-se dizer que elas são reflexo do avanço significativo no desempenho dos alunos do 9ำ do Ensino Fundamental em relação a conteúdos básicos de Estatística, destacando assim, a eficácia da sequência didática, na qual puderam coletar, organizar e representar seus dados, como sugerido nos PCN.

Com relação à Estatística, a finalidade é fazer com que o aluno venha a construir procedimentos para coletar, organizar, comunicar dados, utilizando tabelas, gráficos e representações que aparecem frequentemente em seu dia-a-dia. Além disso, calcular algumas medidas estatísticas como média, mediana e moda com o objetivo de fornecer novos elementos para interpretar dados estatísticos (BRASIL, 1998, p. 52).

Para denotar os avanços, ilustra-se a seguir os resultados obtidos com a aplicação do pré e pós-teste. 
Quadro 8 - Síntese da análise e discussão de dados

\begin{tabular}{|c|c|c|c|c|}
\hline Questão & Conteúdo & Objetivo & $\begin{array}{l}\text { Pré-teste }(\% \\
\text { de acertos) }\end{array}$ & $\begin{array}{l}\text { Pós-teste } \\
\text { (\% de } \\
\text { acertos) }\end{array}$ \\
\hline 1a) & $\begin{array}{c}\text { Média } \\
\text { aritmética }\end{array}$ & $\begin{array}{l}\text { Verificar a habilidade do } \\
\text { aluno em determinar a } \\
\text { média aritmética. }\end{array}$ & $25 \%$ & $87,5 \%$ \\
\hline 1b) & $\begin{array}{c}\text { Média } \\
\text { aritmética }\end{array}$ & $\begin{array}{l}\text { Verificar a habilidade do } \\
\text { aluno em determinar a } \\
\text { média aritmética com a } \\
\text { inferências de novos dados. }\end{array}$ & $25 \%$ & $75 \%$ \\
\hline 2 & $\begin{array}{l}\text { Representação } \\
\text { tabular }\end{array}$ & $\begin{array}{l}\text { Verificar a habilidade do } \\
\text { aluno em realizar a leitura } \\
\text { em uma tabela simples. }\end{array}$ & $25 \%$ & $87,5 \%$ \\
\hline 3 & $\begin{array}{l}\text { Representação } \\
\text { gráfica }\end{array}$ & $\begin{array}{l}\text { Verificar a habilidade do } \\
\text { aluno em realizar a leitura } \\
\text { de dados em um gráfico de } \\
\text { barras }\end{array}$ & $0 \%$ & $37,5 \%$ \\
\hline 4a) & Mediana & $\begin{array}{l}\text { Verificar a habilidade do } \\
\text { aluno em identificar a } \\
\text { mediana }\end{array}$ & $12,5 \%$ & $62,5 \%$ \\
\hline 4b) & Moda & $\begin{array}{l}\text { Verificar a habilidade do } \\
\text { aluno em identificar a moda }\end{array}$ & $0 \%$ & $100 \%$ \\
\hline 5a) & $\begin{array}{c}\text { Média } \\
\text { aritmética e } \\
\text { representação } \\
\text { gráfica }\end{array}$ & $\begin{array}{l}\text { Verificar a habilidade do } \\
\text { aluno em determinar a } \\
\text { média aritmética em uma } \\
\text { representação gráfica. }\end{array}$ & $12,5 \%$ & $62,5 \%$ \\
\hline $5 b)$ & $\begin{array}{l}\text { Moda e } \\
\text { representação } \\
\text { gráfica }\end{array}$ & $\begin{array}{llr}\text { Verificar a habilidade do } \\
\text { aluno em determinar a } \\
\text { moda em ama } \\
\text { representação gráfica. }\end{array}$ & $0 \%$ & $87,5 \%$ \\
\hline 6 & $\begin{array}{l}\text { Representação } \\
\text { tabular e gráfica }\end{array}$ & $\begin{array}{l}\text { Verificar a habilidade do } \\
\text { aluno em realizar a } \\
\text { transnumeração, passando } \\
\text { os dados de uma tabela de } \\
\text { dupla entrada para um } \\
\text { gráfico de barras duplas. }\end{array}$ & $12,5 \%$ & $75 \%$ \\
\hline
\end{tabular}

\section{Fonte: Autores}

Os resultados apresentados mostram a contribuição de uma sequência didática para o processo de ensino e aprendizagem de conteúdos de Estatística, bem como o desenvolvimento de conhecimentos estatísticos considerados essenciais para se atuar na sociedade, uma vez que a média do pré-teste foi de $12,5 \%$ e passou a ser de $75 \%$ com os resultados dos pós-teste. 


\section{Considerações finais}

O presente estudo possibilitou investigar as dificuldades apresentadas por alunos do $9^{\circ}$ ano do Ensino Fundamental, e com bases nelas desenvolver uma sequência didática de conteúdos para a apropriação de conceitos estatísticos. Reforça-se aqui, que um conceito não é adquirido em algumas aulas e para isso é necessário o trabalho contínuo com esses conceitos. A intenção é que no Ensino Fundamental os conceitos que fazem parte da Estatística comecem a ser desenvolvidos e que esse trabalho persista em anos posteriores.

No pré-teste, os alunos apresentaram um fraco desempenho, entretanto, após uma intervenção de ensino, percebe-se que houve um avanço significativo no desempenho em medidas de tendência central, leitura e interpretação de gráficos e tabelas, conteúdos explorados na aplicação da sequência didática. Constata-se esse aspecto ao comparar o desempenho dos alunos no pré-teste com o pós-teste, na qual a média de acertos passou de $12,5 \%$ para $75 \%$. Dessa forma, parece que uma sequência didática com conteúdos de Estatística pode contribuir com a aquisição de conhecimentos estatísticos.

\section{Referências}

BRASIL, Ministério da Educação. Secretaria de Ensino Fundamental. Parâmetros Curriculares Nacionais: ensino fundamental ( $5^{\mathrm{a}}$ a $8^{\mathrm{a}}$ série)/matemática. Brasília (DF): MEC/SEF, 1998.

Ministério da Educação. 5a Olimpíada Brasileira de Matemática das Escolas Públicas: nível 2, $7^{\underline{a}}$ e $8^{\underline{a}}$ séries ( $8^{\circ}$ e $9^{\circ}$ anos) do Ensino Fundamental. Brasília (DF): MEC/SEF, 2009.

DAMIN, W. Ensino de Estatística para os anos finais do Ensino Fundamental. 2014. Número total de folhas. Dissertação (Mestrado em Ensino de Ciência e Tecnologia) Universidade Tecnológica Federal do Paraná. Ponta Grossa, 2014.

ESTEVAM, E. J. G. (Res)significando a Educação Estatística no Ensino Fundamental: análise de uma sequência didática apoiada nas Tecnologias de Informação e Comunicação. 2010. 211 f. Dissertação (Mestrado em Educação). Universidade Estadual Paulista “Júlio de Mesquita Filho", Presidente Prudente (SP), 2010.

EVANGELISTA, M. B.; GUIMARÃES, G. L. Escalas representadas em gráficos: Um estudo de intervenção com alunos do 5 ano. Revista Portuguesa de Educação, 2015, 28(1), pp. 117-138.

LEITE, A. P. F. Estimativa de medidas de tendência central: uma intervenção de ensino. 2010. 160 f. Dissertação (Mestrado Profissional em Ensino de Matemática) Pontifícia Universidade Católica de São Paulo, São Paulo (SP), 2010. Disponível em: $<w w w . p u c s p . b r / p o s / e d m a t / m p / d i s s e r t a c a o / a n a \_p a u l a \_l e i t e . p d f>$. Acesso em: 27 mai. 2013. 
LOPES, C. A. E. A probabilidade e a estatística no ensino fundamental: uma análise curricular. Dissertação (Mestrado). Faculdade de Educação da UNICAMP, Campinas, 1998.

O conhecimento profissional dos professores e suas relações com estatística e probabilidade na educação infantil. 2003. $281 \mathrm{f}$. Tese (Doutorado em Educação). Faculdade de Educação, Universidade Estadual de Campinas, Campinas (SP), 2003.

MAGINA, S; et al. Concepções e concepções alternativas de média: Um estudo comparativo entre professores e alunos do Ensino Fundamental. Educar em Revista, Curitiba (PR) n. especial 2, p. 59-72, 2010. Editora UFPR. Disponível em <http://www.scielo.br/pdf/er/nspe2/04.pdf>. Acesso em 07 de jan. 2013.

PARANÁ. Secretaria de Estado da Educação. Diretrizes curriculares da educação básica: Matemática. Paraná: SEED/DEB, 2008.

PAGAN, M. A. A Interdisciplinaridade como proposta pedagógica para o ensino de Estatística na Educação Básica. 2009. 244 f. Dissertação (Mestrado Profissional em Ensino de Matemática), Pontifícia Universidade Católica de São Paulo, São Paulo (SP), 2009.

ROSA, C. C. Um estudo do fenômeno de congruência em conversões que emergem em atividades de modelagem matemática no ensino médio. 2009. 143 f. Dissertação (Mestrado em Ensino de Ciências e Educação Matemática), Universidade Estadual de Londrina, Londrina (PR), 2009.

SÃO PAULO. Secretaria de Estado da Educação do Paraná. Sistema de Avaliação de Rendimento Escolar do Estado de São Paulo: $8^{\text {a }}$ série Ensino Fundamental. Matemática. São Paulo, 2005.

STELLA, C. A. Um estudo sobre o conceito de média com alunos do Ensino Médio. Dissertação (Mestrado em Educação Matemática) Pontifícia Universidade Católica de São Paulo, São Paulo (SP), 2003.

VASCONCELOS, P. R. Leitura e interpretação de gráficos e tabelas: estudo exploratório com alunos da 8ª série do ensino fundamental. 2007. 205 f. Dissertação (Mestrado Profissional em Ensino de Matemática), Pontifícia Universidade Católica de São Paulo, São Paulo (SP), 2007.

WALICHINSKI, D. Contextualização no Ensino de Estatística: uma proposta para os anos finais do Ensino Fundamental. Dissertação (Mestrado Profissional em Ensino de Ciências e Tecnologia). 2012. 150 f. Universidade Tecnológica Federal do Paraná, Ponta Grossa (PR), 2012.

Submissão: $13 / 10 / 2016$

Aceite: 22/03/2017 